\title{
Abordagem sobre cooperativismo entre médicos anestesiologistas: um estudo em uma cooperativa de saúde
}

\author{
Approach to cooperativism among anesthesiological doctors: a study in a medical \\ cooperative
}

\begin{abstract}
Resumo
O presente estudo objetivou avaliar o conhecimento de médicos anestesiologistas da cidade de João Pessoa Paraíba sobre o cooperativismo, além de suas expectativas quanto à sua cooperativa. Para isso, realizou-se uma pesquisa com abordagem exploratória, envolvendo 78 médicos cooperados com exercício profissional na Cooperativa dos Anestesiologistas da Paraíba (Coopanest-PB). Os dados foram coletados mediante entrevista semiestruturada e analisados qualitativamente, por meio da técnica de análise de conteúdo. Após a análise dos dados coletados, emergiram três categorias temáticas a respeito da compreensão sobre o cooperativismo: união de pessoas com interesses comum; melhores resultados econômicos e progresso coletivo para uma valorização profissional. Em relação à expectativa quanto a cooperativa, obteve-se a classificação em três categorias: respeito aos direitos dos cooperados; sustentabilidade e gestão transparente com prestação de contas. Os resultados deste estudo contribuem para reflexão dos médicos cooperados acerca dos princípios cooperativistas como agregadores deste modelo organizacional, promovendo a disseminação do cooperativismo para novos cooperados.
\end{abstract}

Palavras-chave: cooperativismo, sustentabilidade, cooperativas de saúde.

\begin{abstract}
The present study aimed to evaluate the knowledge of anesthesiologists in the city of João Pessoa - Paraíba, about cooperativism and the expectation of their cooperative. The exploratory study involved 78 co-workers with professional practice at the Paraíba Anesthesiologists Cooperative (Coopanest-PB). The data were collected through a semi-structured interview and analyzed qualitatively through the technique of content analysis. In the content analysis of the collected data, three thematic categories for the knowledge about cooperativism emerged: union of people with common interests, better economic results and collective progress for a professional valorization. Regarding the question about the expectation regarding the cooperative, it was classified into three categories: respect for cooperative rights, sustainability and transparent management with accountability. The results of this study contribute to the cooperative doctors in the reflection of the cooperative principles as aggregators of this organizational model, promoting the dissemination of cooperativism to new members.
\end{abstract}

Keywords: cooperativism, sustainability, health cooperatives.

Maria de Fátima Oliveira dos Santos, André Pacelli Bezerra Viana"II, Marília Augusta Raulino Jácome Oliveira dos Santos ${ }^{\mathrm{IV}}$.

'Universidade Federal da Paraíba. PB. fatimadeosantos@hotmail.com

IIUniversidade Federal da Paraíba. PB. andrepacelli@gmail.com

IIIUniversidade Federal da Paraíba. PB. raulino.marilia@gmail.com

IvUniversidade Federal da Paraíba. PB. analais25@hotmail.com 


\section{Introdução}

O Brasil é o sexto país em maior número de habitantes, ultrapassando 208 milhões de pessoas, segundo o IBGE (2019). A atividade econômica e financeira do Brasil se destaca pela presença de indivíduos como pessoas físicas efetivamente ativas no mercado econômico. Essa crescente atuação de indivíduos no mercado econômico contribui para o crescimento de sociedades de pessoas com objetivos comuns, caracterizando então o cooperativismo como forma de organização social. Diante disso, muito se tem discutido sobre a importância do cooperativismo no Brasil, como terceiro mercado financeiro e seus reflexos sociais e econômicos a nível nacional, já que a participação das cooperativas se faz presente em todas as áreas da atividade econômica (CENZI, 2012).

Considerando este segmento de mercado de trabalho, os indivíduos se reúnem em um movimento social, buscando conquistas financeiras e mercadológicas e pautando-se em princípios claros, definidos na filosofia do cooperativismo. Este modelo de organização ganha força a partir da união voluntária de pessoas, conforme a Lei no 5.764/1971, que rege o cooperativismo no Brasil (BRASIL, 2008). Além disso, os princípios do cooperativismo promovem diversos estímulos à participação desses indivíduos no mercado de trabalho, tais como: cooperação entre pessoas, participação de todos nas decisões, retorno dos resultados aos cooperados, ausência de vínculo empregatício e trabalho em conjunto para melhoria de vidas (AMORIM et al., 2018).

É válido registrar que as organizações estão almejando cada vez mais estratégias para se manterem sustentáveis no mercado e capazes de afastarem os obstáculos impostos pelos cenários aos quais estão expostas. Assim, para aumentar suas chances de sobrevivência coletiva, o homem se vale dos modelos de cooperação, desde o início da civilização (GASPARATOS; EL-HARAM; HORNER, 2008). $\mathrm{Na}$ perspectiva de melhorar as relações sociais e o modo de produção, nasce o cooperativismo, caracterizando-se como uma forma de organização aberta, que conecta pessoas de diversos segmentos e se apresenta como modelo econômico sustentável (BIALOSKORKI NETO, 2001).

O surgimento do cooperativismo como movimento social, traduzido numa filosofia de vida, vem compartilhar um modelo socioeconômico capaz de promover o desenvolvimento econômico e bem-estar social, tendo como fundamentos: participação democrática, solidariedade, independência e autonomia (OCB, 2014). As cooperativas têm se apresentado como uma alternativa de negócios, sendo organizadas com peculiaridades econômicas e sociais diferentes das organizações mercantis. Por sua expansão e representatividade econômica, as cooperativas foram divididas em 13 ramos, sendo eles: Agropecuário, Consumo, Crédito, Educacional, Especial, Infraestrutura, Habitacional, Produção, Mineral, Trabalho, Turismo, Transporte e Saúde, sendo este último, o segmento a que se direciona neste estudo.

Nesse sentido, as cooperativas de saúde podem ser compostas pelos diversos profissionais da saúde: fisioterapeutas, enfermeiros, psicólogos, médicos, dentre outros. Os médicos têm se organizado em cooperativas de serviços para atingir seus objetivos enquanto profissionais liberais, fortalecer o cooperativismo como modelo de negócio inteligente e satisfazer suas necessidades, uma vez que esse modelo de gestão se apresenta como um sistema moderno, sustentável e que agrega valor aos sócios médicos (BARBIERI et al., 2010).

O objetivo deste estudo foi avaliar o conhecimento sobre cooperativismo entre médicos anestesiologistas da cidade de João Pessoa Paraíba e suas expectativas quanto à sua cooperativa. A Coopanest-PB foi fundada em 1988 na cidade de João Pessoa e é formada por 150 cooperados, que realizam suas atividades de trabalho médico através de serviços negociados pela cooperativa junto às Operadoras de Plano de Saúde (OPS), hospitais e clínicas da cidade.

Direcionar este estudo à avaliação do conhecimento sobre o cooperativismo é trazer a discussão acerca da importância da sustentabilidade da cooperativa, incluindo o cooperado como agente principal por compor e possuir expectativas acerca de sua cooperativa. Nesse sentido, é sempre oportuno discutir sobre possíveis diferenças de expectativas entre os cooperados, trazendo à luz o 
grau de identificação destes cooperados com o cooperativismo, inclusive proporcionando insights para mudanças e alinhamentos conceituais entre estes cooperados.

\section{Referencial Teórico}

\subsection{Cooperativismo}

O cooperativismo teve origem como organização de trabalhadores na Inglaterra, em 1844 período da Revolução Industrial, em Rochdale. O surgimento se deu por meio do movimento de um grupo de tecelões que fundaram uma cooperativa de consumo denominada Rochdale Society of Equitable Pioners, cujo objetivo era encontrar formas para melhorar a situação econômica dos trabalhadores. Atualmente, o órgão representativo do movimento cooperativista mundial é a Aliança Cooperativa Internacional (ACI) (SALES, 2010).

Na legislação brasileira como caracteriza a Lei № 5.764/71 (Lei que rege o cooperativismo), as cooperativas são sociedades de pessoas, com forma e natureza jurídica próprias, de natureza civil, não sujeitas a falência, constituídas para prestar serviços aos associados, seguindo assim o pressuposto básico da ajuda mútua, onde os associados são tanto donos como usuários dos serviços.

Na visão de Benecke (1980), as cooperativas são reconhecidas legalmente como uma das formas de organização de empreendimentos coletivos. Elas se apresentam como alternativas capazes de unir crescimento econômico e bem-estar social, pois as pessoas estão percebendo o poder da cooperação para o desenvolvimento das sociedades e dos indivíduos. Enquanto modelo de gestão que valoriza o capital humano, em detrimento do lucro, a cooperativa possibilita a um determinado grupo de indivíduos atingirem objetivos específicos, por meio de um acordo voluntário para cooperação recíproca. Para isso, atua no mercado e desenvolve atividades de consumo, produção, crédito, prestação de serviços e comercialização para seus cooperados, sendo responsável por uma parcela significativa da geração de renda e empregos de uma sociedade (WEBERING, 2014).

A Lei do cooperativismo estabelece que a sociedade será administrada por uma Diretoria ou Conselho de Administração, composto exclusivamente de associados eleitos pela Assembleia Geral. Para gerenciar uma cooperativa do ramo da saúde, faz-se necessário a utilização de modelos de boas práticas, como a Governança Corporativa (GC), que têm por finalidade otimizar o desempenho da empresa, visando o objetivo das partes interessadas (BÜTTENBENDER, 2010).

Neste norte, considerando a relevância do mercado de cooperativas do ramo da saúde no Brasil, as cooperativas se apresentam como um modelo sustentável, sendo reguladas pela Agência Nacional de Saúde Suplementar (ANS).

\subsection{Saúde Suplementar}

A demanda por serviços de saúde é um elemento inerente à vida humana e à manutenção desta. Nesse sentido, a Constituição Federal de 1988 reconheceu a relevância deste direito universal, delegando ao Estado o dever de garanti-la a todos os cidadãos. Para a materialização deste direito, o Estado estruturou o Sistema Único de Saúde (SUS), consolidando então a sua obrigatoriedade de promover o bem-estar físico, psíquico e social aos cidadãos brasileiros.

Acerca deste Sistema de Saúde Brasileiro, Malta e Merhy (2001) afirmam que a política de saúde no Brasil foi marcada por uma trajetória de constantes reduções de investimentos, repercutindo nos aspectos acerca da qualidade dos serviços demandados. Assim, ao se considerar as constantes e crescentes demandas pelos serviços de saúde e em contraponto, às reduções de recursos direcionados ao SUS e consequente não suprimento das demandas da população, surge a oportunidade do oferecimento de serviços privados de assistência à saúde, originando então o início da saúde suplementar no cenário brasileiro. 
O segmento da saúde suplementar brasileira possui características próprias quanto à relação entre os atores que figuram neste cenário. Por atores, são definidos: as Operadoras de Planos de Saúde (OPS), que comercializam os serviços de assistência à saúde; os beneficiários, que contratam os planos de saúde e usufruem da assistência; os prestadores, que são contratados pelas OPS para prestarem os serviços de assistência à saúde aos beneficiários e a Agência Nacional de Saúde Suplementar (ANS), figurando como agência reguladora das relações existentes nesse segmento de mercado. Esta função regulatória possui total relação com a existência das múltiplas imperfeições do setor, considerando que estas contribuem para o desequilíbrio econômico e informacional do mesmo (ANDRADE E MAIA, 2009).

O mercado da saúde suplementar é composto por 48,6 milhões de beneficiários, inseridos no público consumidor desses serviços. A ANS divulgou, em junho de 2019, que a taxa de cobertura de planos de saúde da população brasileira é de $25 \%$, ou seja, a cada quatro brasileiros, um tem plano de saúde suplementar, conforme figur abaixo:

Figura 1 - Taxa de cobertura dos planos de assistência médica por unidades da federação (Brasil dezembro/2018)

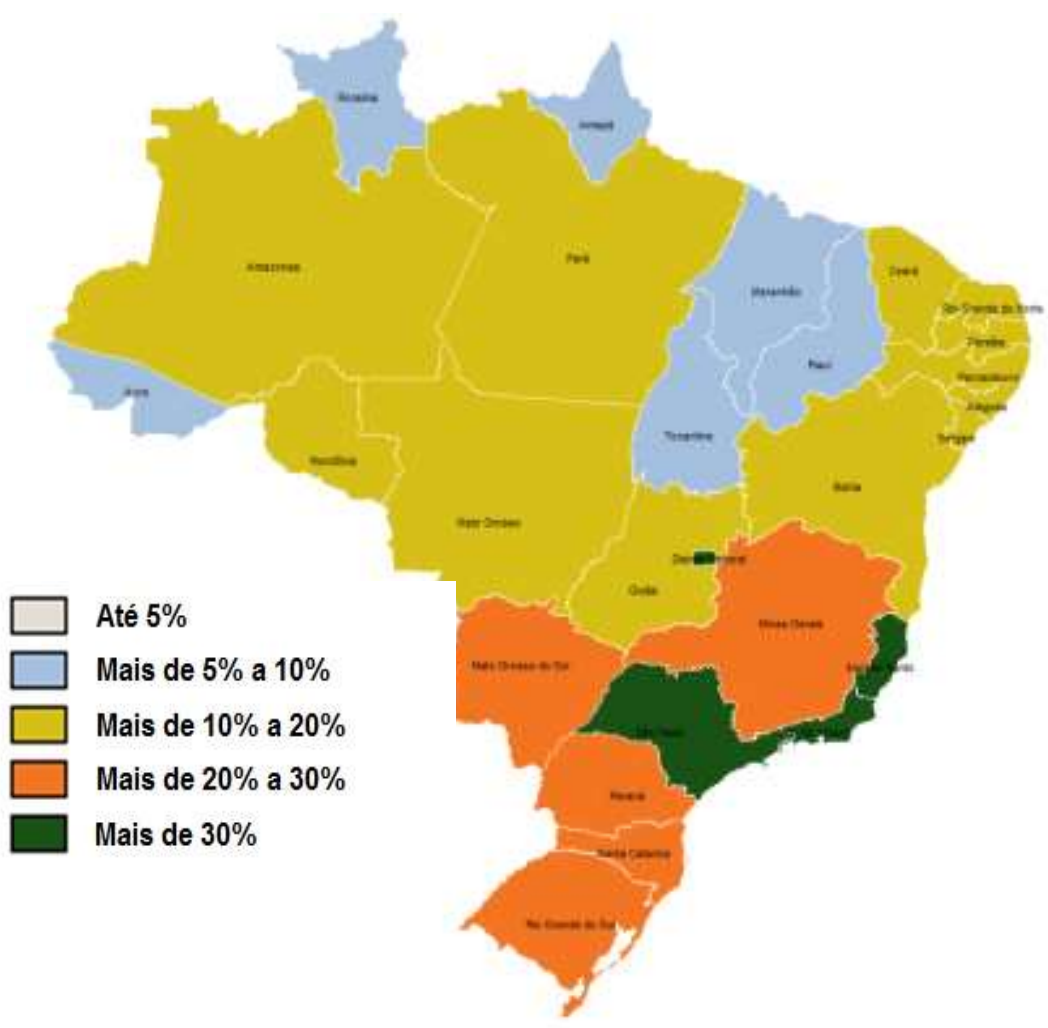

Fonte: Sistema de informações de beneficiários/ANS/MS - 12/2018 e População IBGE/DATASUS/2012.

Estes beneficiários estão segmentados em pelo menos 5 tipos de Operadoras de Planos de saúde, sendo: cooperativas médicas, medicina de grupo, seguradoras, autogestão e filantrópicas, conforme o quadro a seguir: 
Quadro 1 - Quantitativo de beneficiários por modelo de OPS

\begin{tabular}{|l|c|}
\hline \multicolumn{1}{|c|}{ Modelo de OPS } & Quantitativo de beneficiário \\
\hline Cooperativas médicas & 18,3 milhões \\
\hline Medicina de grupo & 17,4 milhões \\
\hline Seguradoras & 6,9 milhões \\
\hline Autogestão & 5 milhões \\
\hline Filantrópicas & 1 milhão \\
\hline
\end{tabular}

Fonte: Elaboração própria (2019) a partir de ANS (2019).

Nesse sentido, esta expansão do mercado da saúde suplementar tem sido acompanhada pela crescente imposição de mecanismos regulatórios, em que as OPS figuram como os principais atores regulados pela ANS, que, por sua vez, cumpre sua finalidade de promover a defesa do interesse público na assistência suplementar à saúde dos brasileiros, por meio da promoção do equilíbrio e sustentabilidade ao mercado de saúde suplementar.

Por se tratar de saúde suplementar, Salvatori e Ventura (2012) consideram que as operações deste mercado necessitam de monitoramento, devido aos riscos vinculados às suas atividades. E sob esta perspectiva, Guimarães e Alves (2009) esclarecem que estes riscos estão atrelados à não previsão, pelas OPS, do gasto futuro com seus beneficiários, incluindo novos procedimentos no rol de cobertura dos planos de saúde, o aumento do custo da assistência (decorrente do avanço tecnológico) e o risco inerente ao negócio, que juntos contribuem para a insolvência deste mercado, comprometendo a assistência aos beneficiários.

Acerca da insolvência, o gráfico 1 demonstra a sucessiva redução no quantitativo de OPS no exercício das suas atividades.

\section{Gráfico 1 - Evolução no quantitativo de Operadoras de planos privados de saúde em atividade no Brasil (dezembro/1999 a maio/2019)}

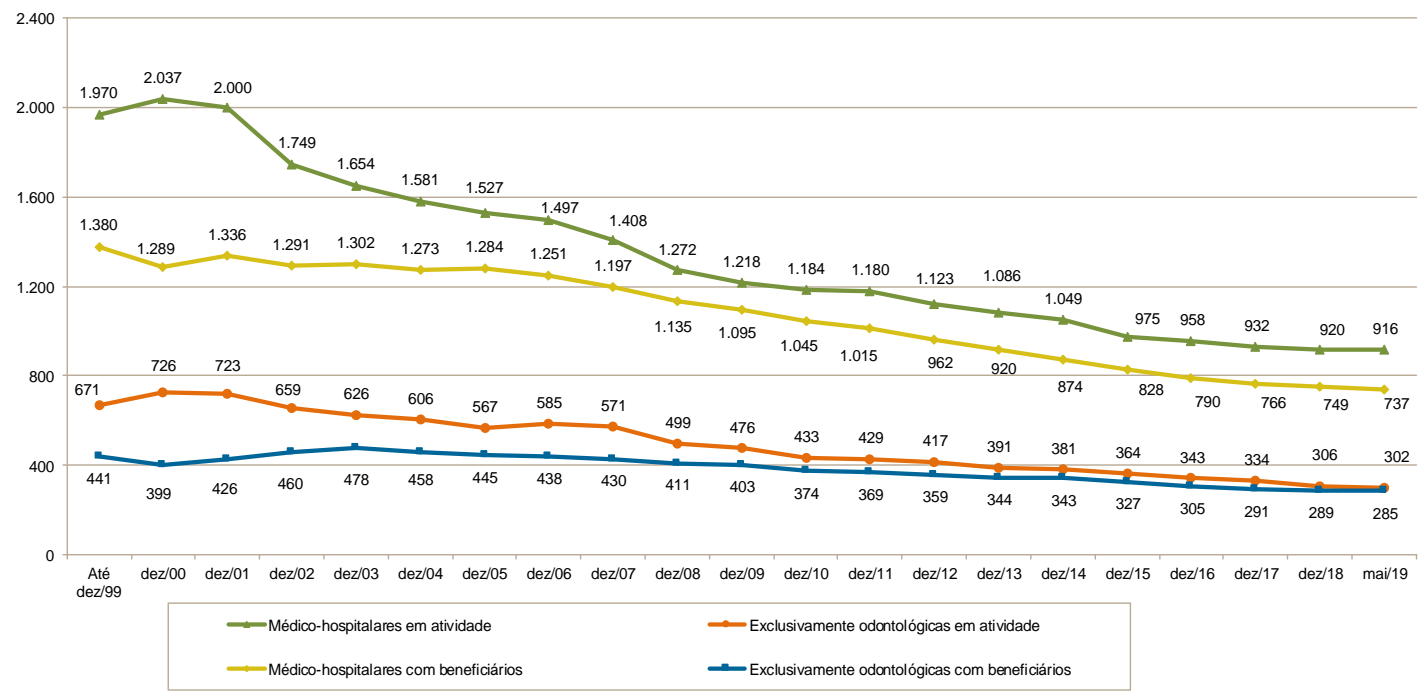

Fonte: Sistema de informações de beneficiários/ANS/MS (05/2019) e CADOP/ANS/MS (05/2019).

A Agência Nacional de Saúde Suplementar monitora e regula medidas para avaliar o equilíbrio econômico-financeiro das cooperativas de saúde, verificando, inclusive, sua capacidade de se manter em dia com as obrigações financeiras junto a seus prestadores (JÁCOME E PAIVA, 2019). 
Sob a ótica da regulação e monitoramento das OPS, a ANS instituiu o índice de sinistralidade, um indicador que permite aos beneficiários, prestadores de serviços, órgão regulador e a própria OPS, a identificação quanto à sustentabilidade e solvência das OPS, que se relaciona em proporção direta com a garantia de prestação dos serviços contratados.

Esse índice é obtido a partir da relação entre as despesas e as receitas assistenciais das OPS. Pires (2008) define a sinistralidade como um índice (em percentual) calculado ao se relacionar os sinistros ocorridos (custos assistenciais) e o prêmio recebido (receitas da assistência), sendo uma métrica utilizada como balizador e parâmetro para as negociações de reajustes dos preços das mensalidades pagas pelos beneficiários às OPS.

A alta sinistralidade tem sido apontada como o principal motivo do encerramento das atividades das OPS, isto porque, em 2018 a média da sinistralidade se apresentou em 83,2\%, o que implica que as OPS possuem apenas $16,8 \%$ das receitas de contraprestação para a manutenção de toda a sua estrutura administrativa e operacional.

Além da sinistralidade, como medida de monitoramento da sustentabilidade e do desempenho econômico-financeiro, a ANS avalia a capacidade das OPS se manterem em dia com as obrigações junto aos seus beneficiários e prestadores, por meio da obrigatoriedade da constituição de provisões técnicas, ativos garantidores e manutenção da margem de solvência.

Nota-se então que os esforços regulatórios da ANS se direcionam ao cumprimento do seu objetivo institucional, que é assegurar a permanência das OPS no mercado e sua prestação de serviços aos beneficiários, respectivamente. Assim, conforme o quadro 1, as cooperativas congregam cerca de 18 milhões dos beneficiários, o que corresponde a aproximadamente $40 \%$ do total de beneficiários existentes no Brasil, tornando então o segmento do cooperativismo em saúde relevante em face de outros modelos de negócio.

\section{Procedimentos Metodológicos}

\subsection{Instrumento de pesquisa e coleta de dados}

Este estudo, de natureza exploratória e descritiva e abordagem qualitativa, foi realizado na Cooperativa de Anestesiologistas da Paraíba (Coopanest-PB), na cidade de João Pessoa. Com vistas a tornar a presente pesquisa representativa (em termos quantitativos), buscou-se divulgar entre os membros da Cooperativa por meios eletrônicos e ainda grupos de comunicação interno. A população foi composta por 150 médicos cooperados que atuam por meio da cooperativa, cuja amostra final foi representada por 78 cooperados que aceitaram participar (52\% dos médicos anestesiologistas), mediante a assinatura do Termo de Consentimento Livre e Esclarecido. Nota-se então que os demais cooperados da cooperativa não participaram por motivos de acessibilidade à cooperativa (no período específico da coleta), restrição de tempo para contribuir com a pesquisa ou até mesmo agendas com compromissos pessoais em outros países.

Ressalta-se que o estudo foi aprovado pelo Comitê de Ética em Pesquisa, sendo registrado sob o protocolo de № 95/17. Os participantes tiveram garantidos, ainda, dentre outros aspectos éticos, o sigilo e o anonimato das informações, conforme preconiza a Resolução № 466/12 do Conselho Nacional de Saúde.

A coleta de dados foi desenvolvida mediante a técnica de entrevista individual semiestruturada, ou seja, por meio de instrumento aplicado presencialmente, realizada no período de janeiro a março de 2019, sendo subsidiada pelas seguintes questões norteadoras: 1) "Qual o seu conhecimento sobre cooperativismo? e 2) 0 que você espera da sua cooperativa?".

Em sequência, a partir das respostas obtidas, foram estabelecidas 3 categorias para cada questão contida no instrumento da entrevista. Para a questão 1) "Qual o seu conhecimento sobre cooperativismo?, as categorias foram: a) União de pessoas com interesse comuns; b) Progredir 
coletivamente para uma valorização profissional; c) Melhores resultados econômicos. Para a questão 2) O que você espera da sua cooperativa?, as categorias foram: a) Sustentabilidade; b) Gestão transparente com prestação de contas; c) Respeito aos direitos dos cooperados.

Após a categorização, os dados suscitados nas entrevistas foram analisados por meio da técnica de análise de conteúdo, que consiste no recorte do conjunto das entrevistas por meio de uma grelha de categorias projetadas sobre os conteúdos, levando-se em consideração a frequência dos temas extraídos do discurso (BARDIN, 2010). Nesse processo, definiu-se o tema como a unidade de significado.

\subsection{Análise dos resultados}

Constituído o corpus do trabalho, ou seja, a transcrição da totalidade das entrevistas, passou-se à fase de sua decomposição em unidades menores ou elementos constitutivos, também chamados unidades de análise, as quais foram agrupadas a partir de características comuns ou aproximadas, gerando categorias temáticas, obedecendo às regras de exclusividade, de homogeneidade e de pertinência.

Após a definição do corpo de categorias e a extração dos segmentos e das frequências de unidades de análise pertinentes a cada categoria, como mencionado, fez-se a análise dos dados por meio de uma abordagem qualitativa, a qual foi ancorada na literatura específica. Buscando-se a organização para futura discussão dos dados, os entrevistados foram identificados pela letra E, seguido do numeral correspondente à ordem das entrevistas, variável de 1 a 78 , número de participantes da pesquisa.

\section{Apresentação dos Resultados}

Os resultados foram levantados com base nas respostas dos 78 médicos anestesiologistas, sócios de uma cooperativa médica do ramo saúde. No que se refere ao perfil da amostra, os dados revelaram que 60 indivíduos (77\%) pertenciam ao sexo masculino e 18 (23\%) ao sexo feminino. Houve boa receptividade entre os participantes. Todos se mostraram interessados e motivados a responder a entrevista, o que contribuiu diretamente para o bom andamento da coleta de dados e posterior análise e discussão dos resultados obtidos.

As unidades de análise (temas) presentes nas falas dos participantes do estudo permitiram gerar três categorias para a seguinte questão norteadora: "O que você entende por cooperativismo?".

Tabela 1 - Categorias e distribuição das unidades de análise referente ao conhecimento de médicos anestesiologistas sobre cooperativismo

\begin{tabular}{l|l|l}
\hline Categorias & \multicolumn{3}{l}{ Unidades de análise } \\
\cline { 2 - 3 } & $\mathrm{n}$ & \multicolumn{2}{l}{$\%$} \\
\hline União de pessoas com interesses comuns & 29 & 53,70 \\
Progredir coletivamente para uma valorização profissional & 15 & 27,78 \\
Melhores resultados econômicos & 10 & 18,52 \\
\hline Total & $\mathbf{5 4}$ & $\mathbf{1 0 0 , 0}$ \\
\hline
\end{tabular}

Fonte: Dados da pesquisa, (2019).

Como se observa na Tabela 2 e partindo do que pressupõe Bardin (2010), quanto mais se fala de um tema, mais importante ele é para quem produz o discurso, consistindo na categoria mais forte em termos de unidade de contexto elementar (UCE). Nesse sentido, é válido ressaltar que as três categorias possuem relação com o conceito do cooperativismo, definido pela Organização das Cooperativas Brasileiras (OCB) como um modelo de negócio que apresenta como premissas a 
promoção do desenvolvimento econômico, com base na união de esforços das pessoas, considerando esse seu capital mais valioso; a participação democrática; a solidariedade e gestão autônoma, que busca a prosperidade coletiva e não a individual.

Em relação a segunda questão contida no instrumento de pesquisa, qual seja: "O que você espera da sua cooperativa?", apresentou as UCE presentes nas falas dos participantes do estudo e permitiram gerar 3 categorias.

Tabela 2 - Categorias e distribuição das unidades de análise referente às expectativas dos médicos anestesiologistas acerca da cooperativa

\begin{tabular}{l|l|l}
\hline Categorias & \multicolumn{2}{l}{ Unidades de análise } \\
\cline { 2 - 3 } & $\mathrm{n}$ & $\%$ \\
\hline Sustentabilidade & 15 & 44,12 \\
Gestão transparente com prestação de contas & 13 & 38,24 \\
Respeito aos direitos dos cooperados & 6 & 17,65 \\
\hline Total & $\mathbf{3 4}$ & $\mathbf{1 0 0 , 0}$ \\
\hline
\end{tabular}

Fonte: Dados da pesquisa, (2019).

Nesse sentido, o maior anseio dos participantes da pesquisa se direciona para a possibilidade de sustentabilidade da Cooperativa, no sentido de permanência no mercado e longevidade de existência, o que sugere a visão de longo prazo de aproximadamente $45 \%$ dos cooperados respondentes.

\section{Discussão dos resultados}

A análise das questões norteadoras do estudo proposto foi realizada qualitativamente mediante a técnica de Bardin (2010), como visto acima. A compreensão sobre "cooperativismo" dos participantes foi classificada em três categorias temáticas: a) união de pessoas com interesses comuns; b) melhores resultados econômicos; c) progredir coletivamente para uma valorização profissional, conforme verificado na Tabela 1.

\section{1 Categoria I - União de pessoas com interesses comuns}

As falas dos participantes estão em consonância com o conceito de cooperativismo, qual seja, organização de pessoas unidas pela cooperação e ajuda mútua e geridas de forma democrática e participativa com objetivos econômicos e sociais comuns (BRASIL,1971).

[...] Grupo de pessoas com os mesmos interesses (E3). [...] União de entidades com objetivos comuns e ajuda mútua (E4). [...] É uma cooperação entre pessoas cujos objetivos de trabalho sejam comuns [...] em relação aquilo que produzem (E5). [...] Grupo de pessoas que se juntam com uma finalidade em comum (E6). [...] Que tem em comum objetivo e fim (E7). [...] Modo de organização laboral na qual um grupo de pessoas se junta para trabalhar em prol de um objetivo comum (E10). [...] Um por todos e todos por um (E12). [...] Conjunto de pessoas reunidas espontaneamente para exercer atividade comum (E15).

Nesse sentido, os médicos cooperados entendem o cooperativismo como a união de indivíduos com interesses comuns, que se utilizam da ajuda mútua para atingir seus objetivos (OLIVEIRA, 2012), sendo necessária uma espécie de coordenação, formal ou não, de suas ações individuais para alcançar um bem coletivo. Desse modo, a sobrevivência do grupo depende de sua capacidade de gerar benefícios líquidos a seus membros, de modo a motivá-los a permanecer e a agir em prol do interesse comum (SERIGATI; AZEVEDO, 2013), como observamos nas falas a seguir. 
[...] Uma relação entre indivíduos que têm objetivos comuns, que na teoria se ajudam mutuamente seguindo com preceitos de igualdade (E17). [...] União de pessoas com objetivo único (E18). [...] Associação de pessoas com interesses assemelhados que se juntam (E19). [...] Cooperativismo é o ato de cooperados se juntarem em prol de um bem comum (E34). [...] Um grupo de pessoas que trabalham em prol da classe que os une, visando o crescimento e o sucesso profissional de todos (E36). [...] União de pessoas que praticam uma mesma atividade com o objetivo de progredir coletivamente. [...] Cooperativismo é uma modalidade na qual as pessoas que possuem os mesmos interesses e atividades se unem em busca de soluções de melhorias (E44).

Dentro desse contexto, parte dos entrevistados considerou como importante a missão da organização de promover a união de pessoas, sendo este um aspecto peculiar do cooperativismo, qual seja, unir pessoas que possuem interesses e objetivos em comum, buscando a valorização do ato cooperativo realizados por estes cooperados:

[...] 0 cooperativismo para mim é um grupo de profissionais que se reúnem em torno de uma missão (E20). [...] União de pessoas com um objetivo comum (E28). [...] Um grupo de pessoas que tem os mesmos interesses (E22). [...] No cooperativismo estão todos em prol do bom funcionamento de uma missão comum (E31). [...] Reunião de indivíduos em favor de uma missão com ajuda mútua (E41). [...] Cooperativismo é a associação de pessoas ou grupos com os mesmos interesses, a fim de obter vantagens comuns (E47). [...] 0 trabalho conjunto de todos por um e de um por todos (E48). [...] União, doação para um fim comum (E52). [...] Junção de pessoas com interesse comum (E58). [...] Cooperativismo é o ato de união entre profissionais de qualquer área (E61). [...] Abdicar de interesses pessoais em favor do coletivo (E66). [...] Conjunto de pessoas com objetivos comuns e ajuda mútua que procura facilitar e propiciar os meios para alcançar esses objetivos (E68). [...] É uma doutrina que reúne um conjunto de pessoas que buscam o mesmo objetivo em prol do desenvolvimento em conjunto (E71). [...] Conjunto de pessoas com finalidade em comum socioeconômica (E72). [...] Associação solidária com um objetivo em comum (E77).

\subsection{Categoria II - Melhores resultados econômicos}

Nas falas transcritas abaixo, verificamos que, conforme a percepção dos cooperados, o cooperativismo proporciona melhores resultados econômicos, eliminando intermediários no processo produtivo e fazendo com que a riqueza alcançada venha a compor os seus patrimônios (DEBOÇÃ; HOCAYEN-DA-SILVA, 2009).

[...] Conseguir receber de forma justa meus honorários médicos (E1). [...] Em busca do êxito de suas atividades socioeconômicas (E3). [...] Um melhor resultado em relação aquilo que produzo (E5). [...] Distribuindo os resultados provenientes destes, ora positivo (E7). [...] Determinando interesse econômico ou social juntam esforços para desenvolver uma atividade (E16). [...] Estratégias de remuneração financeira (E19). [...] Tentar obter lucro na sua atividade econômica, sempre pensando no coletivo (E22). [...] Melhor remuneração e menor tributação, além de ter um papel social (E35). [...] Obter vantagens comuns em suas atividades econômicas [...] 0 fator econômico, o cooperativismo atua no sentido de reduzir custo e oferecer melhor preço nos produtos e serviços (E47). [...] A fim de obter vantagens econômicas e melhorar a lucratividade individual (E67).

A questão econômica é bastante representativa nesse tipo de organização, uma vez que cada sócio cooperado ingressa na cooperativa por meio de uma participação econômica (geralmente explícita nos Estatutos Sociais) e vislumbram que o ato cooperativo seja valorizado e com isto haja retornos financeiros referentes a esta valorização dos serviços ou produtos gerados pelos cooperados.

Os entrevistados manifestaram preocupação pelos resultados financeiros, corroborando com um dos princípios do cooperativismo, qual seja, participação econômica dos membros para viabilidade do negócio. Sendo uma alternativa econômica e social, esse modelo de organização tem se adaptado bem na área da saúde, aglutinando profissionais médicos de diversas especialidades. 


\subsection{Categoria III - Progredir coletivamente para uma valorização profissional}

Nas falas dos participantes do estudo são reveladas suas preocupações em progredir coletivamente. As concepções dos entrevistados guardam relação com a abordagem de Antonialli (2000) de que as cooperativas são organizações democráticas e seus membros a controlam e participam ativamente da formulação das políticas das tomadas de decisões, em que geralmente estas prerrogativas estão estabelecidas no Estatuto Social das cooperativas. Logo, seu progresso se dá através da valorização do seu capital intelectual, que são seus sócios, o que se evidencia nos excertos abaixo:

[...] Produção com o objetivo de um melhor resultado em relação aquilo que produz conjuntamente (E5). [...] Criar oportunidades de trabalho onde a coletividade possa se beneficiar no futuro (E8). [...] Juntos em busca de melhores condições de trabalho, campo de trabalho e valorização (E12). [...] Organização de trabalho onde busca-se uma valorização deste com a manutenção perene da qualidade (E14). [...] Atuam numa frente de trabalho semelhante para alcançar melhores resultados, pensando sempre no bem maior para todos (E21). [...] 0 cooperativismo é pessoas com produto a ser comercializado se reúnem para facilitar negociação do seu produto de forma justa e organizada, obtendo para isto suporte técnico (E25). [...] Buscar o melhor para os cooperados e compradores do serviço da cooperativa (E26). [...] Fortalecer a especialidade e não deixar outros colegas desamparados (E34). [...] 0 cooperativismo é trabalhar em prol da classe que os une, visando o crescimento e o sucesso profissional de todos (E36). [...] Praticam uma mesma atividade com o objetivo de progredir coletivamente (E40). [...] Em comum objetivo, os seus associados valorizam e viabilizam seus negócios no mercado de trabalho (E45). [...] Se associam enquanto força de trabalho no intuito de obterem melhores condições de trabalho e remuneração (E51).

Nesse sentido, os médicos anestesiologistas cooperados evidenciam o reconhecimento da importância de progredir coletivamente, sendo esta unidade de análise compreendida na categoria: "Progredir coletivamente para uma valorização profissional". Assim sendo, a visão dos entrevistados vai ao encontro da concepção de cooperativismo como uma filosofia de vida para construir um mundo melhor, surgida para defender as pessoas da espoliação quando vendiam ou compravam mercadorias, tornando-se uma das melhores alternativas para atender aos interesses da comunidade (FRANTZ, 2003), como observado nas falas a seguir:

[...] Prestar um serviço com dignidade e qualidade tanto para o paciente quanto para os profissionais (E57). [...] Doutrina pautada na interação social dos indivíduos (cooperação) visando o desenvolvimento de seus integrantes (E74). [...] Usa o desenvolvimento de pessoas coletivamente (E75).

Quanto à análise da segunda questão norteadora "O que você espera da sua cooperativa?", foi proposto traçar paralelos entre três categorias que surgiram da questão, que guardam consonância com as políticas do cooperativismo. Estas categorias serão analisadas em separado, incluindo as falas específicas dos cooperados que foram segmentados nestas categorias.

\subsection{Categoria I - Respeito aos direitos dos cooperados}

A Lei no 5.764/71 normatiza os direitos e deveres de cooperado, dentre os quais temos: votar e ser votado, participar de todas as operações da cooperativa, convocar a assembleia, caso seja necessário, bem como pedir esclarecimentos ao conselho de administração, opinar e defender suas ideias, assim como propor ao conselho de administração medidas de interesses da cooperativa (OCERGS, 2017). Na categoria "respeito aos direitos dos cooperados", evidencia-se que os participantes do estudo valorizam os seus direitos, como é possível constatar nas afirmativas adiante:

[...] Espero que respeitem os direitos dos cooperados (E4). [...] Lutar pelos direitos do cooperados (E10). [...] A cooperativa deve ter responsabilidade e compromisso com os direitos dos cooperados (E18).[...] Respeito ao Estatuto Social da cooperativa quanto 
aos direitos dos cooperados (E33). [...] Cumprir as obrigações na defesa dos direitos dos cooperados no que a cooperativa se propõe (E67). [...] Compromisso com os diretos dos cooperados na valorização dos sócios (E43).

\subsection{Categoria II - Sustentabilidade}

Nos depoimentos, identifica-se que a presença da categoria "sustentabilidade" enuncia a preocupação que os médicos cooperados têm com seu negócio, o que vem a corroborar com a afirmativa de Barbieri et al. (2010), de que a dimensão econômica produz preocupação constante na busca da eficiência, sem a qual as organizações não se perpetuariam.

Assim, as falas dos cooperados reconhecem a necessidade das cooperativas serem sustentáveis para obter melhores e maiores receitas de contraprestações, o que requer da organização um maior esforço para atender tecnicamente a tal requisito e caminhar na gestão profissional com projetos de inovação, nível técnico elevado e com visão de longo prazo para os objetivos e metas contidos no planejamento estratégico, conforme sinalizam a seguir:

[...] Espero que a mesma cresça, no cenário político atual, como um modelo sustentável (E2). [...] Fortalecimento e êxito nos projetos socioeconômicos (E3). [...] Manutenção de um mercado de trabalho justo e sustentável (E10). [...] Espero uma organização com êxito para os cooperados (E17). [...] Que a cooperativa melhore cada vez mais a remuneração dos nossos serviços com eficiência (E19). [...] Que cresça cada vez mais, com responsabilidade e organização (E22). [...] Espero que a mesma cresça dentro dos princípios cooperativistas e se torne cada vez mais forte (E 23). [...] Que cumpra sua função com a melhor remuneração e menor custo (E35).

Seguindo essa esteira, as assertivas dos participantes revelam que a "sustentabilidade" é fundamental para a condução da cooperativa nesse mercado competitivo. Nesta perspectiva, Elkington (1994), criador do termo Triple Bottom Line, afirma que a sustentabilidade é o equilíbrio entre os três pilares: ambiental, econômico e social.

Com o mesmo entendimento, a expectativa de uma contribuição progressiva das empresas com a sustentabilidade surge do reconhecimento de que os negócios precisam de mercados estáveis e, portanto, devem possuir habilidades tecnológicas, financeiras e de gerenciamento necessário para possibilitar a transição rumo ao desenvolvimento sustentável, o que contribui diretamente para a permanência das cooperativas no mercado, como fica evidente nos excertos abaixo.

[...] A valorização da especialidade dentro do mercado de trabalho, tornando sustentável através de um objetivo em comum (E45). [...] Uma cooperativa que caminha no crescimento, empreendimento e prosperidade para todos os sócios e outras gerações de cooperados (E54). [...] Que ela continue a agregar os anestesiologistas paraibanos, com a justa valorização dos honorários profissionais (E55). [...] Uma organização que seja um norte para enfrentar o mercado de trabalho (E56). [...] Ofereça condições de trabalho com resultados positivos na prestação dos serviços (E69). [...] Uma cooperativa organizada na forma de gestão profissional, que busca novos mercados de trabalhos para os cooperados (E70). [...] Uma cooperativa dinâmica que continua ampliando seu mercado de trabalho para os sócios, de maneira que não falte trabalho (E72).

\subsection{Categoria III - Gestão transparente com prestação de contas}

Considerando o questionamento: “O que você espera da sua cooperativa?", feito aos participantes do estudo, foi possível categorizar "gestão transparente com prestação de contas". A prestação de contas é um dos pilares da Governança Corporativa e se refere a obrigação da organização tornar os seus atos conhecidos pelos demais sócios/cooperados. Este anseio foi capturado a partir das seguintes argumentações dadas pelos participantes: 
[...] Eu espero receber meus honorários sempre de forma justa conforme meu trabalho (E1). [...] Que seja transparente, democrática e eficiente (E8). [...] Transparência, efetividade, coerência (E12). [...] Diminuir os custos administrativos (E13). [...] Espero uma organização transparente, com propósito, comprometimento e êxito para a cooperativa e cooperados (E17). [...] Que seja mais transparente e igual para todos (E20). [...] Uma cooperativa com ética e transparência nos atos da administração (E21). [...] Controle de receitas e sua distribuição de forma transparente (E25).

Percebe-se, desse modo, a "gestão transparente com prestação de contas", como sendo fundamental nos processos de gestão, podendo esta categoria ter emergido pelo contexto em que as organizações têm buscado as melhores práticas pautadas na governança coorporativa. Assim, no que diz respeito à prestação de contas, os agentes de governança devem atuar de maneira transparente, assumindo integralmente as responsabilidades e consequências de seus atos e omissões (IBGC, 2009).

É possível observar claramente que esta preocupação ocupa o pensamento de parte dos entrevistados. Nessa perspectiva, Pivoto (2015), afirma que a gestão transparente é a obrigação de informar e disponibilizar para as partes interessadas as informações de seus interesses, não apenas aquelas impostas por disposições legais e regulamentares. A partir da gestão transparente com prestação de contas, a cooperativa alcança credibilidade com o cooperado, com a sociedade em geral e ainda com outros possíveis interessados em ingressar no quaro associativo da cooperativa.

[...] Transparência e bom senso (E31). [...] Clareza nas ações com critérios claros na distribuição das atividades, prezando por igualdade no tratamento a todos, diretoria ativa na defesa do cooperado (E37). [...] Uma cooperativa com ética e transparência nos atos da administração (E39). [...] Que tenha um bom controle de contas, com organização e apresentação das contas aos cooperados (E65). [...] Um controle fiscal rigoroso, com transparência nas contas com relatórios, uma gestão com abertura de mercados de trabalho (E77).

A Lei № 5.764/71 estabelece que "a sociedade cooperativa será administrada por uma diretoria ou conselho de administração, composta exclusivamente de associados eleitos pela Assembleia Geral" (AG). Logo, deixa clara a função específica para a qual estes foram eleitos. Esta é a organização formal com hierarquia institucional na qual o associado participará manifestando suas aspirações ou julgando as questões apresentadas pela administração nas Assembleias Gerais Ordinárias e/ou extraordinárias (BRASIL,1971).

Assim, as cooperativas precisam se adequar às mudanças na forma de gestão da organização, com implantação de novas metodologias de gestão e controles internos mais rigorosos, a partir de planejamento estratégico com a participação dos cooperados, enfatizando a educação cooperativista. Entretanto, por não terem em suas competências práticas de gestão, abrangendo planejamento e execução, passam por problemas de controle (ANTONIALLI, 2000).

\section{Conclusões}

O estudo se desenvolveu a partir da necessidade de compreender o que os médicos anestesiologistas sócios de uma cooperativa de serviços médicos da Paraíba obtinham de percepção acerca do cooperativismo e quais eram as suas expectativas quanto a sua cooperativa. Este modelo de sociedade encontra seu início no campo filosófico e sua prática de gestão deve ser pautada em princípios.

Nessas considerações, salienta-se que os dados aqui produzidos revelam um recorte de realidade que traduz experiências e vivências experimentadas de modo particular. Assim, os pesquisadores não pretendem formatar conclusões sistemáticas, mas apenas apresentar ideias e considerações provisórias. Não cabem, desse modo, generalizações, mas, um processo de reflexões que deve ser continuado e que ainda pode ser aplicado em outras cooperativas de especialidade médica no 
mesmo Estado ou até mesmo em outras regiões do País, a fim de que haja o comparativo entre os resultados encontrados.

Uma vez pontuadas essas reflexões, passa-se a sumarizar a impressão do fenômeno observado pelos pesquisadores. Embora o cooperativismo seja bem diversificado em seus ramos, ele incorpora questões subjetivas. Para atender cabalmente aos requisitos legais propostos na lei do cooperativismo № 5.764/71, faz-se necessária a disseminação entre seus sócios do que venha a ser o cooperativismo e o que a cooperativa representa para eles, bem como a razão da indispensabilidade de se priorizar ações de educação cooperativistas.

Ficou evidenciado que o cooperativismo representa a união de pessoas com objetivos comuns em busca de melhores resultados econômicos e com a intenção de progredir coletivamente para uma valorização profissional, sendo essas as expectativas do cooperado acerca da cooperativa, enquanto organização. Um componente que merece destaque é a percepção correta manifesta pelos participantes da pesquisa, sugerindo que o princípio de Educação cooperativista têm tornado os cooperados partícipes conceitualmente sobre a estrutura e práticas de suas respectivas cooperativas. Seguindo essa esteira, as falas estão permeadas de termos correlatos a respeito dos direitos dos cooperados, à sustentabilidade e à gestão transparente com prestação de contas. Fica claro, desse modo, a essência do modelo cooperativista ideal e trazido pelos princípios e legislação, mas também, fica evidente que esta essência para além dos dispositivos legais, mas sim, essa essência como presente nos atos e concepções dos cooperados.

Ante o exposto, o estudo possibilita um novo olhar concernente ao entendimento desses profissionais sobre o que é cooperativismo, sendo uma ferramenta de suma importância para fortalecer o modelo cooperativista e aumentar sua credibilidade. 0 cooperativismo no curso de profissionais liberais é de extrema relevância, pois permite que o profissional exerça sua atividade de maneira diversificada, aliada ao processo de ajuda mútua, possibilitando melhor remuneração e novos campos de trabalho junto à cooperativa como intermediária de serviços. No entanto, cabe a reflexão acerca do alinhamento entre as expectativas dos cooperados em relação a cooperativa e as expectativas da cooperativa em relação ao cooperado, pois, visto que haja uma falta de alinhamento entre estas, a implantação dos princípios e a práticas destes poderá ser comprometida.

Nesse contexto, evidencia-se a relevância da reflexão sobre o que o cooperativismo representa para os seus cooperados, aspecto que pode exercer grande influência sobre a atuação do profissional enquanto cooperado e as perspectivas de sua trajetória enquanto permanecer na cooperativa Outro aspecto importante, resultado desta pesquisa, é a capacidade reflexiva gerada nos cooperados, os fazendo revisitar ou rememorar conceitos e expectativas sobre a cooperativa. Nesse sentido, esta pesquisa contribui para ressaltar a importância do envolvimento dos dirigentes das cooperativas na disseminação do quinto princípio do cooperativismo, qual seja, educação cooperativista, treinamento e formação no conhecimento do que vem a ser o cooperativismo e o que é fazer parte de uma cooperativa, desse modo o alinhamento trará ou contribuirá para o alcance dos objetivos da cooperativa e dos cooperados.

\section{Referências}

AMORIM, K. et al. A influência da educação financeira na inserção dos investidores no mercado de capitais brasileiro: um estudo com discentes da área de negócios. RACE - Revista de Administração, Contabilidade e Economia, v. 17, n. 2, p. 567-590, 28 ago. 2018.

ANDRADE, Mônica V.; MAIA, Ana C.; Diferenciais de utilização do cuidado de saúde no sistema suplementar brasileiro. Revista de Estudos Econômicos, ISSN: 0101-4161, Universidade de São Paulo (USP), São Paulo, v. 39, n. 01, pp. 7-38, jan./mar. 2009. Disponível em: http://www.scielo.br/pdf/ee/v39n1/v39n1a01.pdf. Acesso em: 09 de jun. 2019.

ANS - Agência Nacional de Saúde Suplementar. 2019. Disponível em: www.ans.gov.br. Acesso em: 04 abr. 2019. Caderno de Informação de Saúde Suplementar. Rio de Janeiro: dez. 2017. 
ANTONIALLI, Luiz Marcelo. Influência da mudança de gestão nas estratégias de uma cooperativa agropecuária. Rev. adm. contemp., Curitiba, v. 4, n. 1, p. 135-159, abr. 2000.

ARAUJO, Ângelo A. da S.; SILVA, José R. S. Análise de tendência da sinistralidade e impacto na diminuição do número de operadoras de saúde suplementar no Brasil. Ciência saúde coletiva, Rio de Janeiro, v. 23, n. 8, p. 2763-2770, ago. $2018 . \quad$ Disponível em: http://www.scielo.br/scielo.php?script=sci_arttext\&pid=S141381232018000802763\&lng=pt\&nrm=is o. Acesso em: 18 jun. 2019.

BARBIERI, J. C. et al. Inovação e Sustentabilidade: Novos Modelos e Proposições. RAE-Revista de Administração de Empresas, v. 50, n. 2, p.146-154, abr./jun. 2010.

BARDIN, L. Análise de conteúdo. 5. ed. Lisboa: Edições 70, 2010.

BENECKE, Dieter W. Cooperação e desenvolvimento: O papel das cooperativas no processo de desenvolvimento econômico nos países de terceiro mundo. Porto Alegre: Coojornal; Recife: Assocene, 1980.

BIALOSKORKI NETO, S. Cooperativas: economia, crescimento e estrutura de capital. São Paulo: OCESP/SESCOOP-SP, 2001.

BRASIL. Lei no 5.764, de 16 de dezembro de 1971. Institui o regime jurídico das sociedades cooperativas. Disponível em: http://www.planalto.gov.br/ccivil_03/leis/5764.htm. Acesso em: 02 mar. 2019.

BRASIL. Presidência da República. Casa Civil. Lei no 5764, de 16 de dezembro de 1971. Diário Oficial da República Federativa do Brasil, Brasília, DF, 16 dez. 1971.

BÜTTENBENDER, Pedro Luís. Importância dos supermercados em cooperativas de produção: um estudo comparativo em seis cooperativas no Rio Grande do Sul. In: BÜTTENBENDER, Pedro Luís. Cooperativismo na Região Nordeste do Rio Grande do Sul: experiências de gestão cooperativa e de promoção do desenvolvimento. Porto Alegre/RS: Editora Sescoop/RS, 2010. p. 49-72.

CARVALHO, R. R. P.; FORTES, P. A. de C.; GARRAFA, V. A saúde suplementar em perspectiva bioética. Rev. Assoc. Med. Bras., São Paulo, n. 59, v. 6, dez. 2013.

CENZI, Neiri Luiz. Cooperativismo: desde as origens ao projeto de lei da reforma ao sistema cooperativo brasileiro. 1. ed. Curitiba: Juruá, 2012.

CHADDAD, F. R.; COOK, E. M. L. Entendendo Novos Modelos Cooperativos: Uma Propriedade Tipologia dos Direitos de Controle. Revisão de Economia Agrícola, v. 26, ed. 3, p. 348-360, 2004.

DEBOÇÃ, L. P.; HOCAYEN-DA-SILVA, A. J. Aspectos de estruturação organizacional em cooperativas agropecuárias: um estudo de caso. Revista de Economia e Administração, v. 8, n. 4, p. 391-408, out./dez. 2009.

ELKINGTON, J. Towards the suitable corporation: win-win-win business strategies for sustainable development. California Management Review, v. 36, n. 2, p. 90-100, 1994.

FRANTZ, W. Caminhos para o desenvolvimento pelo cooperativismo. Ijuí: Ed. UNIJUÍ, 2003.

GASPARATOS, A.; EL-HARAM, M.; HORNER, M. A critical review of reductionist approaches for assessing the progress towards sustainability. Environmental Impact Assessment Review, v. 8, n. 4-5, p. 286-311, 2008.

GOVERNO DO BRASIL. População brasileira ultrapassa 208 milhões de pessoas. IBGE, 2018. Disponível em:http://www.brasil.gov.br/noticias/cidadania-e-inclusao/2018/08/populacao-brasileira ultrapassa-208-milhoes-de-pessoas-revela-ibge. Acesso em: 25 de maio de 2019.

GUIMARÃES, André L. de S.; ALVES, Washington O. Prevendo a insolvência de operadoras de planos de saúde. Revista de Administração de Empresas (RAE), ISSN: 0034-7590, Fundação Getúlio Vargas, Escola de Administração de Empresas de São Paulo, v. 49, n. 4, pp. 459-471, out./dez., 2009. Disponível em: http://www.scielo.br/pdf/rae/v49n4/v49n4a09.pdf. Acesso em: 12 jun. 2019.

IBGC - Instituto Brasileiro de Governança Corporativa. Código das Melhores Práticas de Governança Corporativa. 4. ed. São Paulo, SP: IBGC, 2009. 
JÁCOME, Marilia A. R.; PAIVA, Simone B. A regulação como propulsora de práticas de controle interno na saúde suplementar. Revista Contemporânea de Contabilidade, Florianópolis, v. 16, n. 39, p. 134-155, out. 2019. ISSN 2175-8069. Disponível em: https://periodicos.ufsc.br/index.php/contabilidade/article/view/21758069.2019v16n39p134/4274 1. Acesso em: 09 abr. 2020. doi: https://doi.org/10.5007/2175-8069.2019v16n39p134

JÁCOME, Marilia A. R.; PAIVA, Simone B. Guia das melhores práticas de governança para as cooperativas. São Paulo: IBGC, 2015. p. 15-16.

IBGE - Instituto Brasileiro de Geografia e Estatística. Dados Infográficos. 2019. Acesso em: 04 fev. 2019.

MACIEL, Ana Paula Blanke et al. Governança em Cooperativas: Aplicação em uma Cooperativa Agropecuária. Artigos Tecnológicos: Governança em Cooperativas, Rio de Janeiro, v. 22, n. 4, p. 600 619, jul./ago. 2018.

MALTA, Deborah C.; MERHY, Emerson E. Buscando novas modelagens em saúde: as contribuições do Projeto Vida e do Acolhimento para a mudança do processo de trabalho na rede pública de Belo Horizonte, 1993-1996. Revista Eletrônica do DMPS, Unicamp, 01 dez. 2001. Disponível em: http://www.uff.br/saudecoletiva/professores/merhy/artigos-02.pdf. Acesso em: 18 jun. 2019.

MAZZA, Vera Maria de Souza. Cooperativismo e Sustentabilidade: Um Estudo Sobre a Produção Científica na Base Web of Science. Revista de Gestão e Organizações Cooperativas, [S.l.], v. 1, n. 1, p. 1222, nov. 2014.

MEINEN, Ê.; PORT, M. O cooperativismo de crédito: ontem, hoje e amanhã. Brasília, DF: CONFEBRAS, 2012.

OCB - Organização das Cooperativas Brasileiras. 2014. Disponível em: http://www.ocb.org.br. Acesso em: 19 mar. 2019.

OCERGS - Organização das Cooperativas do Rio Grande do Sul. Expressão do Cooperativismo Gaúcho, 2015. Brasília: OCERGS, 2017.

OCERGS - Organização das Cooperativas do Rio Grande do Sul. Resolução Sescoop/RS. 02/2006. Aprova o Programa UNI_SESCOOP/RS e fixa as diretrizes e as normas para a concessão de bolsas de estudo. Disponível em: http://www.ocergs.com.br. Acesso em: 28 mar. 2019.

OLIVEIRA, Djalma de Pinho Rebouças de. Manual de gestão das cooperativas: uma abordagem prática. 6. ed. São Paulo: Atlas, 2012.

PIVOTO, Dieisson. Governança Cooperativa: uma análise dos problemas dos direitos de propriedades difusos nas cooperativas agropecuárias do Rio Grande do Sul. Porto Alegre: Sescoop/RS, 2013. 130p.

SALES, J. E. Cooperativismo: Origens e Evolução. Revista Brasileira de Gestão e Engenharia, Centro de Ensino Superior de São Gotardo, n. I, jan./jun. 2010.

SALVATORI, Rachel T.; VENTURA, Carla A. A. A agência nacional de saúde suplementar - ANS: onze anos de regulação dos planos de saúde. Organizações \& Sociedade (O\&S), Universidade Federal da Bahia (UFBA), Salvador, ISSN: 1984-9230, v. 19, n. 62, pp. 471-487, jul./set. 2012. Disponível em: https://portalseer.ufba.br/index.php/revistaoes/article/view/11208/8117. Acesso em: 12 jun. 2019.

SERIGATI, F. C.; AZEVEDO, P. F. Comprometimento, características da cooperativa e desempenho financeiro: uma análise em painel com as cooperativas agrícolas paulistas. Revista de Administração, v. 48, n. 2, p. 222-238, 2013.

SESCOOP - Serviço Nacional de Aprendizagem do Cooperativismo. Manuais para Capacitação - Módulo I - Curso de Formação Conselheiros Fiscais, 2017.

WEBERING, Susana Iglesias. Autogestão e Cooperação em uma perspectiva cooperativista e sistêmica: o contexto cooperativo espanhol e brasileiro. Rio de Janeiro: UFRJ/COPPE, 2014. 